\title{
PRODUÇÃO DE LIPÍDIOS ATRAVÉS DA BIOCONVERSÃO DA GLICERINA PELA MICROALGA SKELETONEMA COSTATUM
}

\author{
D. A. NOGUEIRA ${ }^{1}$, N. T. RIBEIRO ${ }^{1}$ e C. A. V. BURKERT ${ }^{1}$ \\ ${ }^{1}$ Universidade Federal do Rio Grande, Escola de Química e Alimentos \\ E-mail para contato: nogueiradaniali@yahoo.com.br
}

\begin{abstract}
RESUMO - O objetivo deste trabalho foi estudar a produção lipídica da microalga Skeletonema costatum, comparando a utilização da glicerina de grau analítico (GGA) e da glicerina residual (GR) como fonte de carbono em diferentes concentrações $(0,03 \mathrm{M}, 0,05 \mathrm{M}$ e $0,07 \mathrm{M})$, caracterizando a biomassa obtida em termos de conteúdo lipídico e perfil de ácidos graxos. Skeletonema costatum se destacou na produção lipídica, obtendo-se $67,78 \pm 1,41 \%$ e $66,40 \pm 0,46 \%$ de lipídios na concentração de $0,05 \mathrm{M}$ de GGA e GR, respectivamente. Nesta mesma concentração, o perfil de ácidos graxos, entre os ácidos graxos saturados, destacou-se o ácido palmítico, com 18\% (GGA) e 17,8\% (GR). Do total de ácidos graxos monoinsaturados, $47,8 \%$ e $29,2 \%$ para GR e GGA, respectivamente, destaca-se o ácido oléico (38\% e 19,7\%, respectivamente). Os ácidos graxos poliinsaturados, os ácidos $\gamma$ - linolênico e $\alpha$ - linolênico destacaram-se quando o cultivo foi realizado com GGA, resultando em $13,4 \%$ e $13,7 \%$ do total, respectivamente.
\end{abstract}

\section{INTRODUÇÃO}

$\mathrm{Na}$ indústria alimentícia, as biomassas derivadas de microalgas são comercializadas como alimento natural ou suplemento alimentar, sendo encontradas formulações em pó, tabletes, cápsulas ou extratos. Conforme Pulz e Gross (2004) são também incorporadas em massas, petiscos, doces, bebidas, entre outros, tanto como suplemento nutricional quanto como corantes naturais. Além disso, a biomassa microalgal é rica em ácidos graxos poliinsaturados, como ácido eicosapentaenoico (EPA) e ácido docosaexaenoico (DHA), capazes de prevenir doenças cardiovasculares, câncer, diabetes, doenças inflamatórias, entre outras, segundo Derner et al. (2006). Os triacilgliceróis nas microalgas correspondem à maior fração lipídica e, em algumas espécies, os ácidos graxos poli-insaturados representam entre 25 e $60 \%$ dos lipídios totais.

De acordo com Bertolli e Fernandes (2008) a microalga Skeletonema costatum é um importante constituinte do fitoplâncton marinho em função de sua ocorrência em grandes quantidades. Por apresentar rápido crescimento, é amplamente utilizada para alimentação de larvas de crustáceos e moluscos bivalves, e também em estudos de auto-ecologia. Segundo o 
trabalho de Borges (2005) a microalga ainda é identificada como uma espécie com potencial de uso para a captura do $\mathrm{CO}_{2}$ e produção de biodiesel.

Por outro lado, um aspecto importante na obtenção do biodiesel de forma sustentável é o destino a ser dado à glicerina obtida no processo. A conversão da glicerina por via biotecnológica em produtos de importância comercial constitui uma das mais promissoras alternativas para seu aproveitamento (Silva et al., 2009). A glicerina residual resultante da síntese do biodiesel usualmente apresenta 55 - 90\% de pureza. O restante consiste de triacilgliceróis não convertidos, metanol ou etanol não convertido, biodiesel, sabões e outros (Amaral et al., 2009). No entanto, o uso de glicerina residual ainda é pouco explorado em cultivos mixotróficos de microalgas, sendo importante estudos para avaliar a capacidade de assimilação do glicerol por diferentes espécies de microalgas, bem como o impacto sobre o crescimento microalgal e a composição da biomassa.

Neste contexto, o objetivo deste trabalho foi avaliar o acúmulo de lipídios no cultivo mixotrófico da microalga marinha Skeletonema costatum, comparando a utilização da glicerina de grau analítico (GGA) e glicerina residual (GR) como fonte de carbono em diferentes concentrações, caracterizando a biomassa obtida em termos de perfil de ácidos graxos.

\section{MATERIAL E MÉTODOS}

Nos experimentos foi utilizada a microalga marinha Skeletonema costatum, cedida pelo Laboratório de Biologia Marinha e Biomonitoramento (LABIOMAR) da Universidade Federal da Bahia - UFBa. O volume de inóculo adicionado correspondeu a $10 \%$ do volume de meio estéril. O micro-organismo foi mantido em fotobiorreatores, do tipo Erlenmeyer de 1L, contendo $900 \mathrm{~mL}$ do meio Conway (Walne, 1966), utilizando água marinha com ajuste de salinidade em 28 u.p.s. Os fotobiorreatores foram dispostos em uma estufa com fotoperíodo (Eletrolab, modelo EL 202, Brasil). A concentração inicial de biomassa microalgal foi de 0,13 g. $\mathrm{L}^{-1}$. As condições de cultivo foram: temperatura de $24 \pm 1^{\circ} \mathrm{C}$, irradiância de $3000 \mathrm{Lx}$, fotoperíodo integral e agitação constante através da injeção de ar estéril, sem medição de vazão. Nos cultivos mixotróficos foram testados os seguintes meios de cultivo: meio Conway adicionado de GGA ou GR em diferentes concentrações de glicerol, previamente corrigidas conforme a pureza $(0,03 \mathrm{M}, 0,05 \mathrm{M}$ e $0,07 \mathrm{M})$. A GR com 82,09\% de pureza conforme laudo fornecido pela empresa BS BIOS Indústria e Comércio de Biodiesel Sul Brasil S/A, localizada em Passo Fundo/RS, sendo o coproduto da transesterificação de óleo de soja e metanol em catálise alcalina. Os experimentos foram conduzidos em triplicata e alíquotas dos cultivos foram retiradas a cada $24 \mathrm{~h}$, para a determinação da biomassa, por medida da absorvância a $680 \mathrm{~nm}$. Ao término dos experimentos foi realizada a quantificação de lipídios utilizando o método de Bligh e Dyer (1959). Para a determinação do perfil de ácidos foi utilizada a cromatografia gasosa (Cromatógrafo gasoso Varian, modelo 3400CX, EUA), após 
a esterificação dos triacilgliceróis pelo métodos de Metcalfe e Schmitz (1996).Os resultados foram submetidos à análise de variância (ANOVA), a fim de verificar diferenças significativas entre as diferentes concentrações de glicerina de grau analítico e entre as diferentes concentrações de glicerina residual, a 95\% de confiança $(p \leq 0,05)$. As diferenças entre os cultivos com glicerina de grau analítico e glicerina residual foram avaliados pelo Teste t a $95 \%$ de confiança.

\section{RESULTADOS E DISCUSSÃO}

Conforme a Tabela 1, ao analisar os teores de lipídios acumulados ao longo do cultivo utilizando a GGA, verifica-se que na concentração de $0,05 \mathrm{M}$ alcançou-se o melhor resultado, de $67,78 \pm 1,41 \%$, diferindo das demais concentrações, que alcançaram $61,46 \pm 0,82 \%(0,03$ M) e 56,74 $\pm 0,67 \%(0,07 \mathrm{M})$. Quando utilizada a GR nas concentrações de 0,05 M e 0,07 M, não diferiram estatisticamente entre si, obtendo-se teores de lipídios de 66,40 $\pm 0,46 \%$ e 65,51 $\pm 1,05 \%$, respectivamente, mas diferiram de $0,03 \mathrm{M}(60,36 \pm 0,62 \%)$.

Ao comparar as diferentes fontes de glicerina, verifica-se que nas concentrações de 0,03 M e 0,05 M a produção de lipídios não foi afetada pela substituição pela glicerina residual, não havendo diferenças significativas, enquanto que para a concentração de $0,07 \mathrm{M}$ verificase que o uso da glicerina residual contribuiu positivamente para o acúmulo de lipídios, gerando um acréscimo de 56,74 $\pm 0,67 \%$ para $65,51 \pm 1,05 \%$.

Tabela 1 - Conteúdo lipídico da microalga Skeletonema costatum*

\begin{tabular}{ccc}
\hline & \multicolumn{2}{c}{ Lipídios m/m (\%)** } \\
\hline Concentração & GGA & GR \\
\hline $0,03 \mathrm{M}$ & $61,46 \pm 0,82^{\mathrm{b}, \mathrm{A}}$ & $60,36 \pm 0,62^{\mathrm{b}, \mathrm{A}}$ \\
$0,05 \mathrm{M}$ & $67,78 \pm 1,41^{\mathrm{a}, \mathrm{A}}$ & $66,40 \pm 0,46^{\mathrm{a}, \mathrm{A}}$ \\
$0,07 \mathrm{M}$ & $56,74 \pm 0,67^{\mathrm{c}, \mathrm{B}}$ & $65,51 \pm 1,05^{\mathrm{a}, \mathrm{A}}$ \\
\hline
\end{tabular}

*Letras minúsculas iguais representam que não há diferenças significativas entre linhas e letras maiúsculas iguais representam que não há diferenças significativas entre colunas a $95 \%$ de confiança $(\mathrm{p}<0,05)$.

** Em base seca.

De acordo com a Tabela 2, os ácidos graxos com maior representatividade na biomassa para a microalga foram: o ácido hexadecanoico (16:0, ácido palmítico), com um teor de 18,0\% (GGA) e 17,8\% (GR); o ácido hexadecaenoico (16:1, ácido palmitoleico), variando de 7,5\% a 4,4\%; o ácido octadecenoico (18:1 n-9, ácido oleico), variando de 19,7\% para 38,0\%, e os ácidos octadecatrienoicos $\gamma$ - linolênico (18:3 n-6), e $\alpha$-linolênico (18:3n-3), variando de $13,4 \%$ a $6,3 \%$, e de $13,7 \%$ a $3,5 \%$, respectivamente. 
Tabela 2 - Perfil de ácidos graxos da microalga Skeletonema costatum cultivada em meio contendo $0,05 \mathrm{M}$ de GGA e GR

\begin{tabular}{lcc}
\hline Acido graxo & GGA & GR \\
\hline 12:0 - ácido dodecanoico & 1,7 & - \\
14:0 - ácido mirístico & 4,5 & 1,7 \\
15:0 - ácido pentadecanoico & - & - \\
16:0 - ácido palmítico & 18,0 & 17,8 \\
17:0 - ácido heptadecanoico & 2,9 & \\
18:0 - ácido octadecanoico & 4,8 & 7,5 \\
24:0 - ácido tetracosanoico & - & 2,1 \\
\hline Total de AGS (\%) & 31,9 & 29,1 \\
\hline 14:1 - ácido tetradecenoico & 0,8 & 1,7 \\
16:1 - ácido palmitoleico & 7,5 & 4,4 \\
17:1 - ácido heptadecenoico & 0,5 & - \\
18:1 n-9 - ácido oleico & 19,7 & 38,0 \\
24:1 n-9 - ácido tetracosenoico & 0,7 & 3,7 \\
\hline Total de AGM (\%) & 29,2 & 47,8 \\
\hline 18:2 n-6 - ácido linoleico & 3,0 & 5,8 \\
18:3 n-6 - ácido $\gamma$-linolênico & 13,4 & 6,3 \\
18:3 n-3 - ácido $\alpha$-linolênico & 13,7 & 3,5 \\
20:4 n-6 - ácido araquidônico & 6,7 & 1,1 \\
20:5 n-3 - ácido eicosapentanoico (EPA) & - & - \\
22:2 - ácido docosadienoico & 1,5 & 3,9 \\
22:6 n-3 - ácido docosahexaenoico (DHA) & 0,6 & 2,5 \\
\hline Total de AGPI (\%) & 38,9 & 23,1 \\
\hline Total (\%) & 100 & 100 \\
\hline
\end{tabular}

Com relação ao grau de insaturação, a microalga apresentou percentuais mais elevados de ácidos graxos monoinsaturados (AGMs) em meio contendo GR $(47,8 \%)$ do que em meio contendo GGA $(29,2 \%)$. Para os ácidos graxos saturados (AGSs) estes percentuais foram de $31,9 \%$ (GGA) e 29,1\% (GR). Teores similares de ácidos graxos foram encontrados por Borges - Campos et al. (2010), em trabalho utilizando Skeletonema costatum, obtendo para os AGSs um percentual de 34,4\% e para os AGMs um percentual de 43,9\%.

Para os ácidos graxos poli-insaturados (AGPIs) obteve-se 38,9\% destes compostos quando utilizada a GGA e $23,1 \%$ quando utilizada a GR. O teor de AGPIs encontrado por Aznay et al. (2004) foi de $26,1 \%$, resultado este próximo do teor encontrado neste trabalho quando utilizado a GR $(23,1 \%)$. No presente caso, com o uso da GGA, foram obtidos maiores teores dos ácidos $\gamma$ - linolênico (18:3 n-6) e $\alpha$-linolênico (18:3 n-3), com 13,4\% e 13,7\%, respectivamente.

Além dos AGPIs já comentados, foram também identificados na biomassa os ácidos graxos essenciais da família n-6, sendo eles o ácido linoleico (18:2 n-6), variando de 3,0\% (GGA) a 5,8\% (GR); o ácido araquidônico (20:4 n-6), com teor de 6,7\% em GGA e apenas 1,1\% para GR; o ácido docosadienoico, com percentual mais elevado em GR, de 3,9\%; e o 
ácido docosahexaenoico - DHA (22:6 n-3), com 2,5\% em GR, este conhecido por suas propriedades anti-inflamatórias e com funções imunológicas, assim como função na formação, desenvolvimento e funcionamento do cérebro e da retina, sendo predominante na maioria das membranas celulares desses órgãos (Martin et al., 2006).

\section{CONCLUSÕES}

Com base no acima exposto, pode-se afirmar que é possível utilizar a glicerina residual oriunda da produção do biodiesel no cultivo da microalga Skeletonema costatum, aproveitando desta forma o coproduto com impurezas, sem tratamentos prévios, de baixo custo, permitindo agregar valor à cadeia produtiva do biodiesel. O perfil de ácidos graxos foi alterado pela substituição da GGA pela GR, destacando-se os incrementos importantes de AGMs passando de 29,2\% (GGA) para e 47,8\% (GR), indicando que mudanças nas condições do cultivo, como o caso da pureza do substrato, pode permitir a manipulação destes perfis. Soma-se a isto o fato de que os diferentes perfis podem sugerir diferentes aplicações, como na alimentação humana, na indústria farmacêutica, de cosméticos e de biocombustíveis, entre outras.

\section{REFERÊNCIAS}

AMARAL, P. F. F.; FERREIRA, T. F.; FONTES, G. C.; COELHO, M. A. Z. Glycerol valorization: New biotechnological routes. Food Bioprod Process., v. 87, p. 179-186, 2009.

AZNAY, M.G.; LÓPEZ, T.R.; VILLARREA. Y.M. Evaluación de tres cepas de Thalassiosira en dos medios de cultivo para su uso en el desarrollo de Litopenaeus vannamei. In: III CONGRESO IBEROAMERICANO VIRTUAL DE ACUICULTURA, 2004, Habana. Comunicación Científica...Cuba: CIVA 2004, p. 218223.

BERTOLLI, L. M.; FERNANDES, L. F. P. O gênero Skeletonema greville (Bacillariophyta) ao longo de um gradiente ambiental no Rio Guaraguaçu, litoral do Paraná, Brasil. In: XII CONGRESSO BRASILEIRO DE FICOLOGIA, 11, 2008, Águas Claras. Anais...Brasília: 2008. p. 133-134.

BLIGH, G. E.; DYER, J. W. A rapid method of total lipid extraction and purification. Can. J. Biochem. Physiol., v. 37, p. 911-917, 1959.

BORGES - CAMPOS, V.; BARBARINO, E.; LOURENÇO, S. L. Crescimento e composição química de dez espécies de microalgas marinhas em cultivos estanques. Cienc. Rural., v. 40, n. 2, p. 339-347, 2010. 
BORGES, L. V. Caracterização do potencial de absorção do dióxido de carbono atmosférico por microalgas utilizadas na aquicultura para a geração de um mecanismo de desenvolvimento limpo (MDL). 2005. 57 f. Dissertação (Mestrado em Aquicultura) Universidade Federal do Rio Grande, Rio Grande, 2005.

DERNER, R. B.; OSHE, S.; VILLELA, M.; CARVALHO, S.; FETT, R. Microalgas, produtos e aplicações. Cienc. Rural., v. 6, p. 1959-1967, 2006.

MARTIN, C. A.; ALMEIDA, V. V.; RUIZ, M. R.; VISENTAINER, J. E. L.; MATSHUSHITA, M.; SOUZA, N. E.; VISENTAINER, J. V. Ácidos graxos poliinsaturados ômega-3 e ômega-6: Importância e ocorrência em alimentos. Rev. Nutr., v. 19, p. 761-770, 2006.

METCALFE, L. D. A. A.; SCHIMITZ, J. R. Rapid preparation of fatty acid esters from lipids for gas liquid chromatography. Anal. Chem. v. 38, p. 510, 1966.

PULZ, O.; GROSS, W. Valuable products from biotechnology of microalgae. Appl Microbiol Biot., v. 65, p. 635-648, 2004.

SILVA, G.P.; MACK, M.; CONTIERO, J. Glycerol: A promising and abundant carbon source for industrial microbiology. Biotechnol Adv., v. 27, p. 30-39, 2009.

WALNE, P. R. Experiments in the large scale culture of the larvae of Ostreaedulis. Fish Invest., v. 25, p. 1-53, 1966. 